\title{
Two-Dimensional van der Waals Supramolecular Frameworks from Co-hosted Molecular Assembly and $\mathrm{C}_{60}$ Dimerization
}

Xin Zhang, ${ }^{1 \dagger}$ Xing Fan,${ }^{2 \dagger}$ Gangqiang Zhu, ${ }^{1}$ Yitao Wang, ${ }^{3}$ Haoxuan Ding, ${ }^{3}$ Haiping Lin,,${ }^{2}$ Youyong $\mathrm{Li}^{2}{ }^{2}$ Qing Li, ${ }^{2}$ Jianzhi Gao, ${ }^{1 *}$ Minghu Pan, ${ }^{1,4 *}$ Quanmin Guo ${ }^{3 *}$

${ }^{1}$ School of Physics and Information Technology, Shaanxi Normal University, Xi'an 710119, China

2 Institute of Functional Nano and Soft Materials (FUNSOM) \& Collaborative Innovation Center of Suzhou Nano Science and Technology, Soochow University, Suzhou 215123 China

${ }^{3}$ School of Physics and Astronomy, University of Birmingham, Birmingham, B15, United Kingdom

${ }^{4}$ School of Physics, Huazhong University of Science and Technology, Wuhan 430074, China

Initial growth of $\mathrm{C}_{60} 2 \mathrm{D}$ crystal
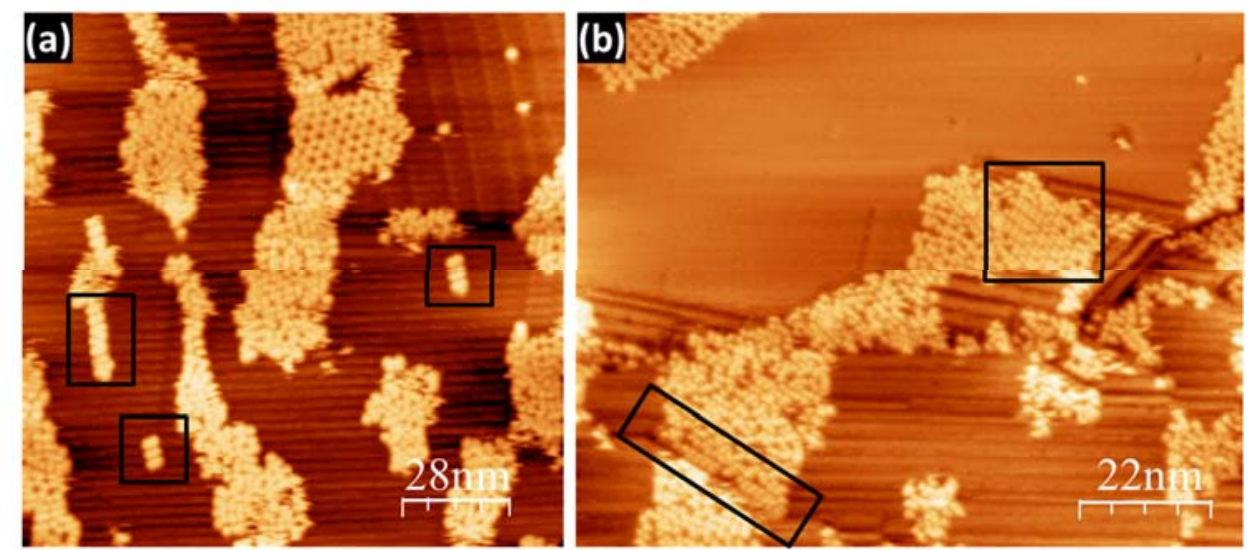

Figure $\mathrm{S} 1$. The initial growth of $\mathrm{C}_{60} 2 \mathrm{D}$ crystal at RT. (a) $\mathrm{V}_{\text {bias }}=1.2 \mathrm{~V}, \mathrm{I}_{\mathrm{t}}=300 \mathrm{pA}$ and image size: $85 \mathrm{~nm}$; (b) $\mathrm{V}_{\text {bias }}=-1.5 \mathrm{~V}, \mathrm{I}_{\mathrm{t}}=50 \mathrm{pA}$ and image size: $90 \mathrm{~nm} \times 110 \mathrm{~nm}$; the areas marked with black rectangles show the appearance of $\mathrm{C}_{60}$ pairs.

The stability of $\mathrm{C}_{60} 2 \mathrm{D}$ crystal
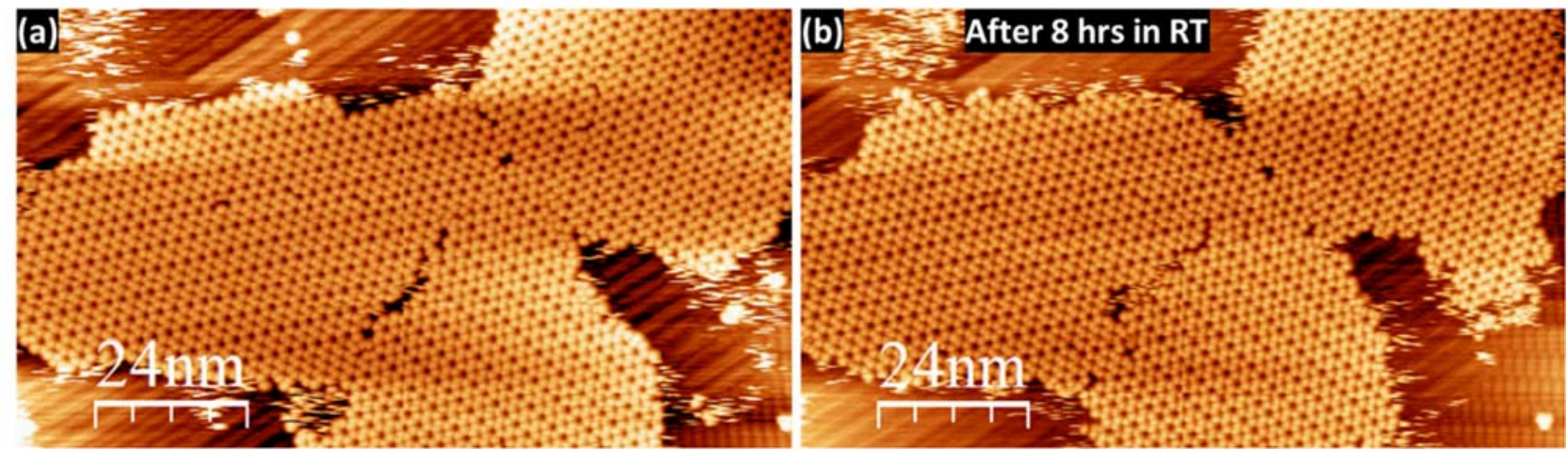

Figure S2. The stability of $\mathrm{C}_{60} 2 \mathrm{D}$ crystal at RT. (a) an original patch of $\mathrm{C}_{60} 2 \mathrm{D}$ crystal; (b) after staying at RT about 8 hours; both images are taken with $\mathrm{V}_{\text {bias }}=1.0 \mathrm{~V}, \mathrm{I}_{\mathrm{t}}=100 \mathrm{pA}$. 
Further depositing $\mathrm{C}_{60}$ molecules onto the porous $\mathrm{C}_{60}$ framework
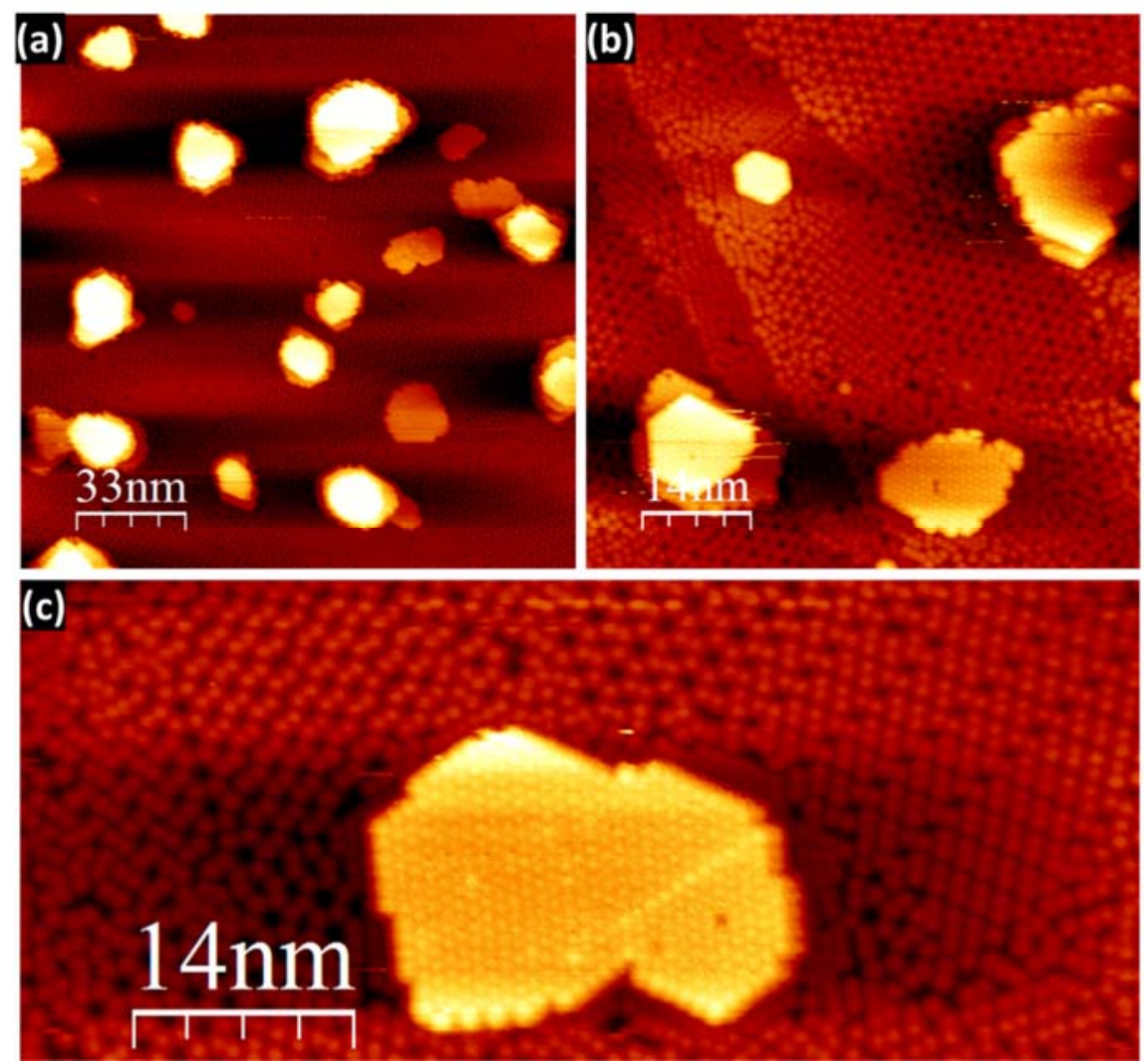

Figure $\mathrm{S} 3$. Further depositing $\mathrm{C}_{60}$ molecules onto the porous $\mathrm{C}_{60}$ framework. (a) $\mathrm{V}_{\text {bias }}=1.8 \mathrm{~V}, \mathrm{I}_{\mathrm{t}}=300 \mathrm{pA}$ and image size: $165 \mathrm{~nm}$; (b) $\mathrm{V}_{\text {bias }}=1.5 \mathrm{~V}, \mathrm{I}_{\mathrm{t}}=300 \mathrm{pA}$ and image size: $70 \mathrm{~nm}$; (c) High resolution image shows both close-packed $\mathrm{C}_{60}$ molecules on multilayers island and porous $\mathrm{C}_{60}$ framework in background, $\mathrm{V}_{\text {bias }}=1.8 \mathrm{~V}, \mathrm{I}_{\mathrm{t}}=300$ pA.

\section{STM images taken at $77 \mathrm{~K}$ with various biases}

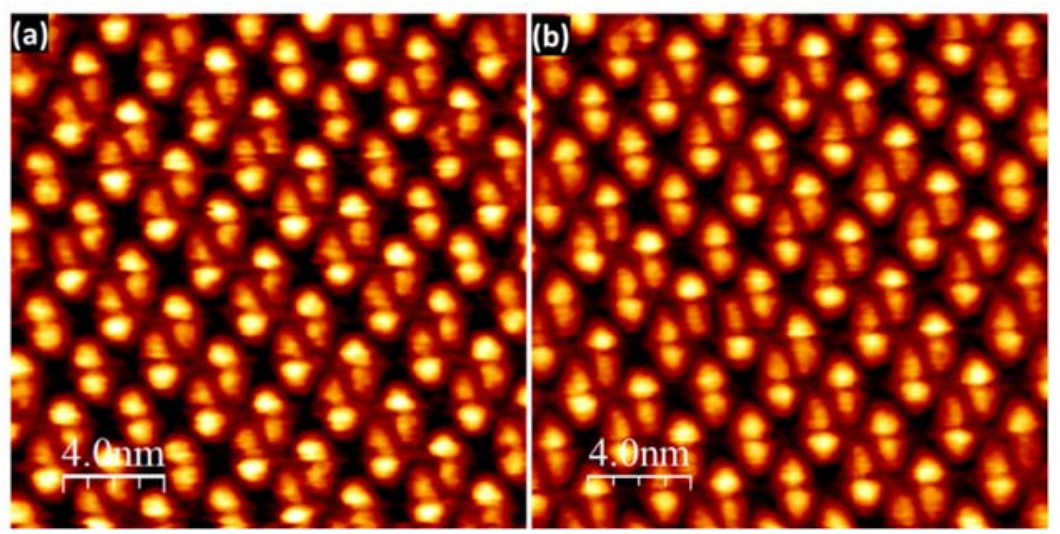

Figure S4. STM images taken at $77 \mathrm{~K}$ with various biases. (a) $\mathrm{V}_{\text {bias }}=-0.3 \mathrm{~V}, \mathrm{I}_{\mathrm{t}}=200 \mathrm{pA}$ and image size: $20 \times 20 \mathrm{~nm}^{2}$; (b) $\mathrm{V}_{\text {bias }}=+0.3 \mathrm{~V}, \mathrm{I}_{\mathrm{t}}=200 \mathrm{pA}$; both images shows a feature of one bright and one dark for the $\mathrm{C}_{60}$ dimers.

\section{Optimized structure of two $\mathrm{C}_{60}$ molecules, calculated isosurfaces and STM simulations}



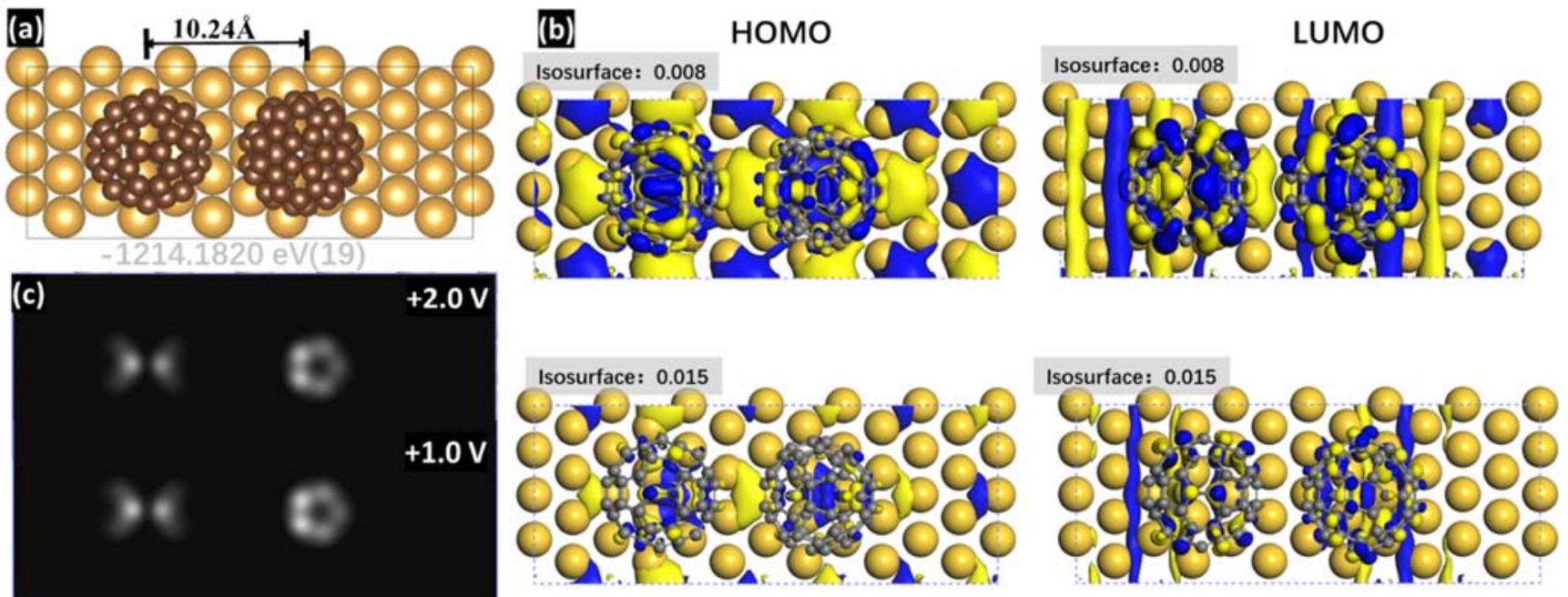

Figure S5. (a) A ball-stick model shows an optimized structure of two $\mathrm{C}_{60}$ molecules with a distance of $10.24 \AA$.

(b) The calculated isosurfaces of 0.008 and 0.015 for the HOMO and LUMO orbitals of two $\mathrm{C}_{60}$, which show no charge-transfer in between. (c)The simulated STM images for such $\mathrm{C}_{60}$ dimer with the biases of $+2.0 \mathrm{~V}$ (upper) and $+1.0 \mathrm{~V}$ (lower). 